\title{
Redetermination of the thermodynamic properties of the solid-solid transition of adamantane by adiabatic calorimetry to investigate the suitability as a reference material for low-temperature DSC-calibration
}

\author{
P.J. van Ekeren*, A.C.G. van Genderen, G.J.K. van den Berg \\ Chemical Thermodynamics Group, Department of Chemistry, Utrecht University, Padualaan 8, 3584 CH Utrecht, The Netherlands \\ Available online 17 April 2006
}

\begin{abstract}
Sub-ambient calibration of DSCs is a problem because there are few reference substances, and every available substance has its drawbacks. One of the possibilities is the low-temperature solid-solid transition of adamantane. High-accuracy adiabatic calorimetry results are, however, only available from one source. Therefore it was decided to measure the transition with our adiabatic calorimeter. Although our results show some deviation from the results reported in the literature source - our transition temperature $(208.0 \mathrm{~K})$ is $0.6 \mathrm{~K}$ lower and our enthalpy of transition $\left(3213 \mathrm{~J} \mathrm{~mol}^{-1}\right)$ is $5 \%$ smaller - we strongly believe this transition can be useful for the calibration of DSCs. Because the heat capacity of the low-temperature phase significantly increases well below the transition temperature, we propose to use a linear base line drawn as a tangent to the (almost) linear heat capacity curve above the transition region and start the integration at the temperature at which the drawn base line crosses the measured curve (at about $190 \mathrm{~K})$. With this integration we found a heat of transition of $3094 \mathrm{~J} \mathrm{~mol}^{-1}\left(=22.7 \mathrm{~J} \mathrm{~g}^{-1}\right)$.
\end{abstract}

(C) 2006 Elsevier B.V. All rights reserved.

Keywords: Calibration; Reference material; Heat capacity; Thermodynamic properties; Phase transition; Adiabatic calorimetry

\section{Introduction}

Everyone performing quantitative measurements using Differential Scanning Calorimetry (DSC) knows that it is very important to calibrate the instrument for temperature as well as for heat flow. Much has been written about calibration procedures and reference substances. A couple of years ago a working group of the German Society for Thermal Analysis, GEFTA, published a series of papers on the temperature $[1,2]$ and the heat flow [3] calibration. A summary was published in reference [4]. The procedures and substances they proposed were adapted by the International Confederation for Thermal Analysis and Calorimetry (ICTAC), and in The Netherlands the Dutch Society for Thermal Analysis and Calorimetry (TAWN) recommends its members to use these procedures.

During one of the TAWN meetings the subject of lowtemperature calibration was discussed. The sub-ambient calibration of DSCs seems to be a problem because there are few

\footnotetext{
* Corresponding author. Tel.: +31 30 2533509; fax: +31 302533946 .

E-mail address: p.j.vanekeren@chem.uu.nl (P.J. van Ekeren).
}

reference substances available. The only two substances that are recommended for sub-ambient calibration in the GEFTA papers [1-4] are:

- Cyclopentane. Two solid-solid transitions (at $-150.77^{\circ} \mathrm{C}$ with heat of transition $69.60 \mathrm{Jg}^{-1}$ and at $-135.09^{\circ} \mathrm{C}$ with heat of transition $4.91 \mathrm{~J} \mathrm{~g}^{-1}$ ) and the melting transition (at $-93.43^{\circ} \mathrm{C}$ with heat of melting $8.63 \mathrm{~J} \mathrm{~g}^{-1}$ ) may be used. The substance is, however, a liquid with a very high vapour pressure at room temperature. Because of this handling is very difficult and it can only be used with hermetically sealed crucibles.

- Water. Melting at $0.00^{\circ} \mathrm{C}$. Here, too, only hermetically sealed crucibles are to be used. The substance is not recommended for heat calibration.

In the TAWN discussion some additional substances were mentioned, among which cyclohexane, 1,2-dichloroethane, mercury, and adamantane. Hakvoort [5] performed measurements and concluded that mercury (provided that the oxide layer of aluminium crucibles remains intact) and adamantane are very 
well suitable for sub-ambient calibration. Later, Hakvoort et al. reported that adamantane is also very suitable for calibration of a DSC in the cooling mode because it shows no significant supercooling [6-8] and that, in comparison with other compounds for low-temperature calibration, it is easy to handle because it has a low vapour pressure at room temperature [9].

In this paper we will focus on adamantane. To be able to use this substance for calibration of a DSC, the transition temperature and the heat of transition must be known with the highest accuracy. As indicated in the GEFTA papers, it is to be preferred that experimental results obtained with adiabatic calorimeters from different sources are available. For adamantane, however, results obtained by adiabatic calorimetry are, as far as we know, only available from one source.

Chang and Westrum used their adiabatic calorimeter to measure the heat capacities and thermodynamic properties of adamantane; the results were published in two papers [10,11]. They reported a "sharp (apparently first order) transition" in adamantane at $208.66 \mathrm{~K}\left(=-64.49^{\circ} \mathrm{C}\right)$ (temperature converted to ITS-90 value from ITS-48 value [12-14]); the heat of transition was reported as $3376 \mathrm{~J} \mathrm{~mol}^{-1}\left(=24.8 \mathrm{~J} \mathrm{~g}^{-1}\right)$.

As described above, for use as a calibration substance, it is important that data are available from different independent sources. Therefore we decided to measure the low-temperature heat capacities and the solid-solid transition with our adiabatic calorimeter and compare our results with those of Chang and Westrum $[10,11]$. In this paper we will focus on the transition data. A discussion on the complete set of thermodynamic data, including absolute entropies, will be published later [15].

\section{Experimental}

\subsection{The sample}

Our sample of adamantane was obtained from Merck Schuchardt OHG, Germany (Adamantane for synthesis; the purity was indicated as better than $99 \%$ ). We used this sample without further treatment.

The molar mass of adamantane $\left(\mathrm{C}_{10} \mathrm{H}_{16}\right.$; CAS No. 208-32-2) is $136.24 \mathrm{~g} \mathrm{~mol}^{-1}$.

\subsection{The adiabatic calorimeter}

The measurements were performed using one of our homebuilt adiabatic calorimeters (CAL V). The design of the calorimeter was described previously $[16,17]$. The thermometer is a $27 \Omega$ rhodium-iron resistance, which has been calibrated by Oxford Instruments at 33 points between 1.5 and $300 \mathrm{~K}$.

After filling, the calorimeter vessel is evacuated. Then helium gas is admitted to the vessel (up to a pressure of about $1000 \mathrm{~Pa}$ ) to serve as a heat exchange gas. Measurements are made in the intermittent mode: stabilisation periods are followed by input periods under automatic control. During each stabilisation period, the temperature is recorded as a function of time. Between two stabilisation periods, an input period is used to raise the temperature of the sample. The amount of heat added to the calorimeter vessel is measured very accurately. The tem-
Table 1

Overview of the series of measurements performed on adamantane

\begin{tabular}{lrrll}
\hline Series no. & $T_{1}(\mathrm{~K})$ & $T_{2}(\mathrm{~K})$ & $t(\mathrm{stab})(\mathrm{s})$ & $t$ (input) (s) \\
\hline 1 & 78 & 282 & 500 & 708 \\
2 & 6 & 7 & 200 & 188 \\
3 & 9 & 28 & 200 & 188 \\
4 & 8 & 31 & 200 & 188 \\
5 & 32 & 100 & 400 & 708 \\
6 & 102 & 293 & 400 & 458 \\
7 & 294 & 330 & 400 & 558 \\
\hline
\end{tabular}

For each measurement series the temperature range in which measurements were performed is given together with the duration of the stabilisation and input periods.

perature increase, which is caused by this heat input, follows from extrapolation of the temperature-time curves of both stabilisation periods. These data allow for the accurate calculation of the heat capacity and gives the enthalpy increment relative to the start of the measurement series. To obtain the heat capacity of the sample, the heat capacity of the empty calorimeter vessel was subtracted.

According to measurements of standard materials, the uncertainty is approximately $0.2 \%$ of the absolute heat capacity.

\subsection{The measurements}

The calorimeter vessel was filled with an amount of $5.24155 \mathrm{~g}$ $(=0.0384729 \mathrm{~mol})$ adamantane. Seven series of measurements were performed with this sample in the temperature range from 6 to $330 \mathrm{~K}$. An overview of the performed measurements (temperature ranges together with duration of stabilisation and input periods) is given in Table 1. The sample was cooled to liquid nitrogen temperature and series 1 was started (at $77 \mathrm{~K}$ ); this series ended at $282 \mathrm{~K}$. After series 1 the sample was cooled to liquid helium temperature and series 2 and 3 were performed, ending at $28 \mathrm{~K}$. Between series 3 and 4 the sample was cooled down again. The sample was not cooled after each of the following series.

\section{Results and discussion}

The results of the seven measurement series are plotted in Fig. 1. In this figure the results obtained by Chang and Westrum [10] are also plotted. In the transition region the high heat capacity values are not plotted for reasons of clarity. The solid-solid phase transition is clearly observed just above $200 \mathrm{~K}$. For the low-temperature phase our heat capacity data are in excellent agreement with the data of Chang and Westrum [10]. Above about $170 \mathrm{~K}$, up to the transition point, our values are slightly greater than those of Chang and Westrum [10]. Above the transition range, up to $250 \mathrm{~K}$, our heat capacity data are in complete agreement with those of Chang and Westrum [10]. At temperatures above $250 \mathrm{~K}$ our heat capacity data are slightly smaller (up to $0.8 \%$ ) than the values measured by Chang and Westrum [10].

In Fig. 2 our heat capacity data around the transition region are plotted. The transition point, evaluated as the temperature at which the maximum heat capacity was observed, is $208.0 \mathrm{~K}$. This is $0.6 \mathrm{~K}$ lower in temperature than the transition point 


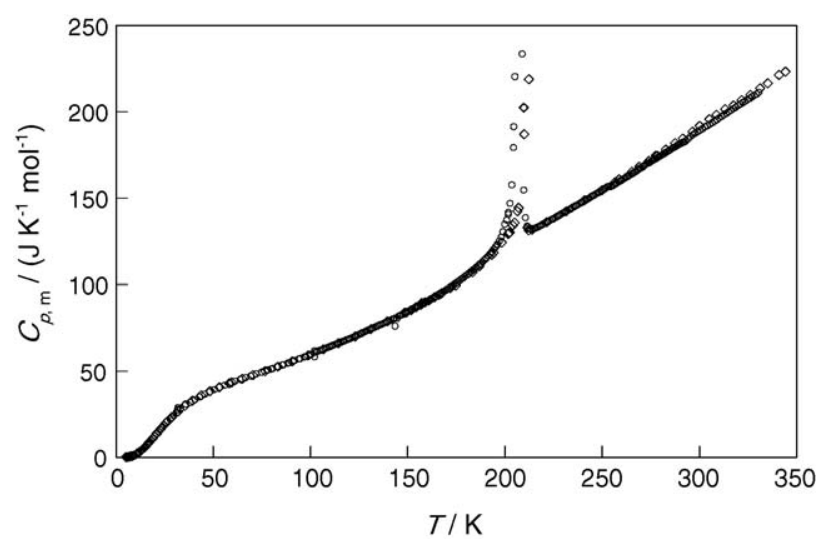

Fig. 1. Experimental molar heat capacities of adamantane. Our results $(\bigcirc)$; Chang and Westrum $(\diamond)[10]$.

reported by Chang and Westrum [10]. For determination of the enthalpy of transition Chang and Westrum appear to have used a linear base line between 175 and $250 \mathrm{~K}$ : they reported a value of $3376 \mathrm{~J} \mathrm{~mol}^{-1}$ [10]. With the same procedure our data result in a value of $3213 \mathrm{~J} \mathrm{~mol}^{-1}\left(=23.58 \mathrm{~J} \mathrm{~g}^{-1}\right)$ for the enthalpy of transition, which is $5 \%$ lower. Although there is a significant increase of the heat capacity well below the transition point, which causes the position of the integration limits to influence the resulting enthalpy of transition value quite significantly, we do not believe that our integration limits differ that much from those of Chang and Westrum that this can account for the observed differences. Therefore the differences in the observed properties are hard
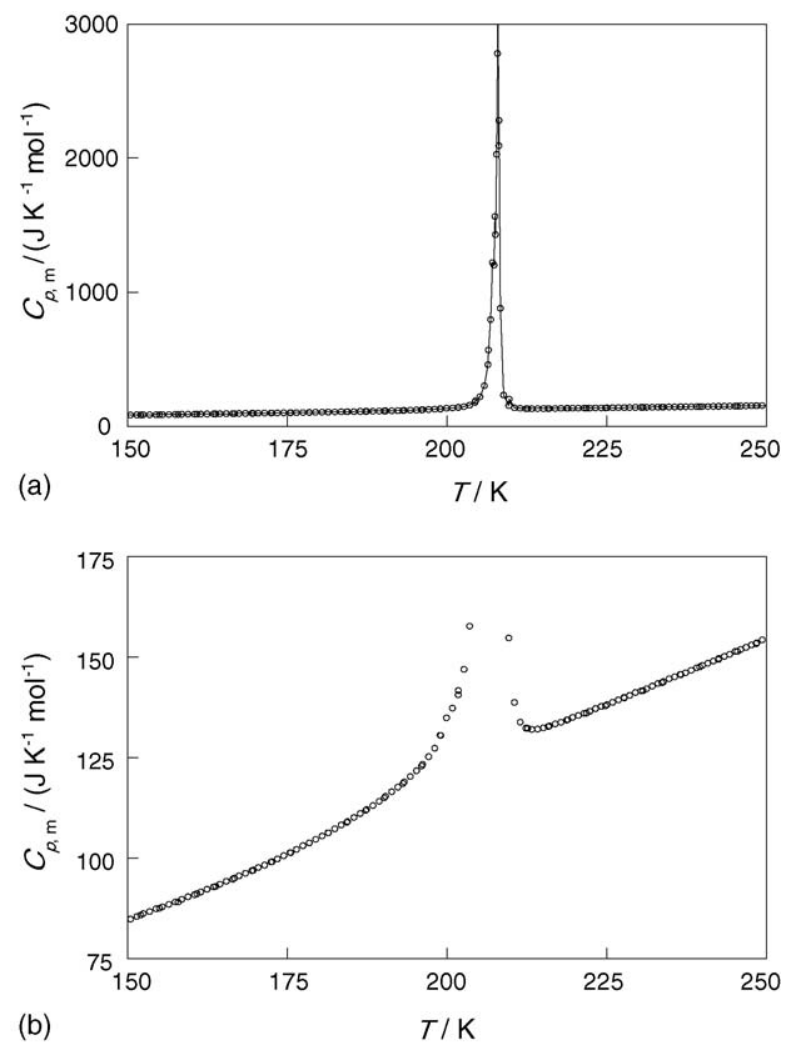

Fig. 2. Experimental molar heat capacities of adamantane in the transition region. (a) Complete transition peak and (b) zoomed on the base line part. to explain: in our laboratory we have performed measurements with our adiabatic calorimeters on many substances and when the same substances were also measured in the laboratory of Westrum, we never found any significant deviations. We therefore assume the observed difference must be related to the used samples of adamantane.

Although the observed differences in transition temperature $(0.6 \mathrm{~K})$ and enthalpy of transition $(5 \%)$ are somewhat disappointing, the substance adamantane may still be useful for the DSC-calibration since all alternatives also seem to have their disadvantages. If the commercially available sample of adamantane from Merck is used, we believe it is best to use our results as reference values: transition temperature $208.0 \mathrm{~K}$ with en estimated uncertainty of $0.2 \mathrm{~K}$ and transition enthalpy $3213 \mathrm{~J} \mathrm{~mol}^{-1}$ $\left(=23.58 \mathrm{~J} \mathrm{~g}^{-1}\right.$; evaluated using a linear base line between 175 and $250 \mathrm{~K}$ ) with an estimated uncertainty of $1 \%$ (the estimated uncertainty is greater than usual because of the difficulty to select the base line).

For the heat calibration of DSCs we suggest another procedure to get round the problem of the integration limits. Since the heat capacity above the transition region shows an almost linear dependence on temperature, a DSC-curve above the transition range should also be (almost) linear. It is therefore quite easy to draw a base line as the extrapolation of the tangent to this linear line back to its intersection with the measured curve. The peak may then be integrated between the intersection point and the end of the peak. In our heat capacity curve the point of intersection is found as $190.4 \mathrm{~K}$. With the suggested base line, and integration between the point of intersection and $250 \mathrm{~K}$, we find a heat of transition of $3094 \mathrm{~J} \mathrm{~mol}^{-1}\left(=22.7 \mathrm{~J} \mathrm{~g}^{-1}\right)$ which may be used as reference value when the procedure outlined in this paragraph is followed. The uncertainty in this value is estimated as $0.5 \%$.

\section{References}

[1] G.H.W. Höhne, H.K. Cammenga, W. Eysel, E. Gmelin, W. Hemminger, Thermochim. Acta 160 (1990) 1-12.

[2] H.K. Cammenga, W. Eysel, E. Gmelin, W. Hemminger, G.W.H. Höhne, S.M. Sarge, Thermochim. Acta 219 (1993) 333-342.

[3] S.M. Sarge, E. Gmelin, G.W.H. Höhne, H.K. Cammenga, W. Hemminger, W. Eysel, Thermochim. Acta 247 (1994) 129-168.

[4] S.M. Sarge, W. Hemminger, E. Gmelin, G.W.H. Höhne, H.K. Cammenga, W. Eysel, J. Therm. Anal. 49 (1997) 1125-1134.

[5] G. Hakvoort, J. Therm. Anal. 41 (1994) 1551.

[6] G. Hakvoort, C.M. Hol, J. Therm. Anal. 52 (1998) 195-202.

[7] G. Hakvoort, C.M. Hol, J. Therm. Anal. Calorim. 56 (1999) 717-722.

[8] G. Hakvoort, C.M. Hol, P.J. van Ekeren, J. Therm. Anal. Calorim. 64 (2001) $367-375$.

[9] G. Hakvoort, C.M. Hol, P.J. van Ekeren, J. Therm. Anal. Calorim. 69 (2002) 333-338.

[10] S.-S. Chang, E.F. Westrum Jr., J. Phys. Chem. 64 (1960) 1547-1551.

[11] E.F. Westrum Jr., P. Phys. Chem. Solids 18 (1961) 83-85.

[12] H. Preston-Thomas, Metrologia 27 (1990) 3.

[13] H. Preston-Thomas, Metrologia 27 (1990) 107.

[14] C.R. Barber, Metrologia 5 (1969) 35-44.

[15] P.J. van Ekeren, A.C.G. van Genderen, G.J.K. van den Berg, J. Therm. Anal. Calorim., in press.

[16] J.C. van Miltenburg, G.J.K. van den Berg, M.J. van Bommel, J. Chem. Thermodyn. 19 (1987) 1129.

[17] J.C. van Miltenburg, A.C.G. van Genderen, G.J.K. van den Berg, Thermochim. Acta 319 (1998) 151. 